\title{
Response to the Letter to the Editor: "The prognostic value of white blood cell count-to-mean platelet volume ratio in patients with acute coronary syndrome"
}

We would like to thank Murat Yuksel et al. [1] for their comments on our article [2]. They have asked if we consider that the elevated levels of mean platelet volume (MPV) and total white blood cell (WBC) count predict cardiovascular events in acute coronary syndrome (ACS) patients; therefore the WBC/MPV ratio (WMR) values may not be considered a good prognostication marker due to dividing WBC by MPV. Although they offered some comments regarding the association of inflammatory markers with ACS, they should focus more on MPV and total WBC count in non-ST elevation ACS (NSTE-ACS) instead of platelet and lymphocyte counts. Given their notions and those mentioned in our article, we propose some points in this letter.

The prognostic role of MPV has been demonstrated among patients with myocardial infarction (MI) [3], however, findings in terms of MPV have not been consistent among NSTE-ACS or NSTEMI. Tekbas et al. [4] have shown that elevated MPV increased the risk of mortality in ST elevation MI (STEMI) during hospitalization, but not in NSTEMI group. Taglieri et al. [5] have also demonstrated that, among NSTE-ACS patients, elevated MPV group was at higher risk for combined cardiovascular death and MI, while the association with each of the endpoints alone has decreased. Furthermore, in another prospective study, MPV was not associated with 6 -month adverse events in NSTE-ACS patients [6]. One reason for this issue can be explained by findings of Rinder et al. [7], who have found that the interaction between platelets and leukocytes at culprit lesion of atherosclerotic plaques, leading to inflammatory pathways and subsequent atherothrombosis, is a dynamic process attributable to platelet activation status and leukocyte adhesion ability. Thus, it is likely that in the progression of NSTE-ACS, both activated and inactivated platelets are involved, which may be suggestive of the fact why increased MPV is not associated with adverse events in NSTE-ACS. Beside the MPV values, the majority of studies have shown that higher total WBC count has been a prognostic marker for patients at greater risk for developing cardiovascular adverse events at follow-up duration in ACS patients [8], MI alone [9], or NSTE-ACS [10].

Taking into account these findings and the prognostic role of WMR as a novel inflammationbased marker reflecting both MPV and WBC count effects in ACS, it seems more likely to consider that the WMR may not be useful in STEMI patients due to a vast amount of studies showing association between elevated MPV and STEMI prognosis. On the other hand, the prognostic ability of WMR in predicting patients at greater risk for worse outcomes in NSTE-ACS may be of great importance because of lack of association between elevated MPV and outcomes of such patients. Further large-scaled prospective study may be useful in elucidating the importance of WMR in the risk stratification and treatment modalities of NSTE-ACS patients.

\section{Conflict of interest: None declared}

\section{References}

1. Yuksel M, Yildiz A, Cayli M. The prognostic value of white blood cell count-to-mean platelet volume ratio in patients with acute coronary syndrome. Cardiol J, 2015; 22: 351-352.

2. Dehghani MR, Rezaei Y, Taghipour-Sani L. White blood cell count to mean platelet volume ratio as a novel non-invasive marker predicting long-term outcomes in patients with non-ST elevation acute coronary syndrome. Cardiol J, 2015; doi: 10.5603/ /CJ.a2015.0015 [Epub ahead of print].

3. Chu SG, Becker RC, Berger PB et al. Mean platelet volume as a predictor of cardiovascular risk: a systematic review and metaanalysis. J Thromb Haemost, 2010; 8: 148-156.

4. Tekbas E, Kara AF, Ariturk $Z$ et al. Mean platelet volume in predicting short- and long-term morbidity and mortality in patients with or without ST-segment elevation myocardial infarction. Scand J Clin Lab Invest, 2011; 71: 613-619.

5. Taglieri N, Saia F, Rapezzi C et al. Prognostic significance of mean platelet volume on admission in an unselected cohort of patients with non ST-segment elevation acute coronary syndrome. Thromb Haemost, 2011; 106: 132-140. 
6. Lopez-Cuenca AA, Tello-Montoliu A, Roldan V et al. Prognostic value of mean platelet volume in patients with non-ST-elevation acute coronary syndrome. Angiology, 2012; 63: 241-244.

7. Rinder HM, Bonan JL, Rinder CS et al. Activated and unactivated platelet adhesion to monocytes and neutrophils. Blood, 1991; 78: 1760-1769.

8. Sabatine MS, Morrow DA, Cannon CP et al. Relationship between baseline white blood cell count and degree of coronary artery disease and mortality in patients with acute coronary syndromes: A TACTICS-TIMI 18 (Treat Angina with Aggrastat and determine Cost of Therapy with an
Invasive or Conservative Strategy-Thrombolysis in Myocardial Infarction 18 trial)substudy. J Am Coll Cardiol, 2002; 40: 1761-1768.

9. Mariani M, Fetiveau R, Rossetti E et al. Significance of total and differential leucocyte count in patients with acute myocardial infarction treated with primary coronary angioplasty. Eur Heart J, 2006; 27: 2511-2515.

10. Dehghani MR, Rezaei Y, Taghipour-Sani L. Superiority of total white blood cell count over other leukocyte differentials for predicting long-term outcomes in patients with non-ST elevation acute coronary syndrome. Biomarkers, 2014; 19: 378-384.

Mohammad Reza Dehghani ${ }^{1}$, Yousef Rezaei ${ }^{2}$

${ }^{1}$ Department of Cardiology, Seyyed-al-Shohada Heart Center, Urmia University of Medical Sciences, Urmia, Iran

${ }^{2}$ Seyyed-al-Shohada Heart Center,

Urmia University of Medical Sciences,

Urmia 5718749441, Iran,

tel: $+98-912-623-1864$,

fax: $+98-443-237-5907$,

e-mail: yousefrezaei1986@gmail.com 